\title{
Toward an Understanding of Tropical Cyclone Formation with a Nonhydrostatic, Mesoscale-Convection-Resolving Model $^{\S}$
}

\author{
Masanori Yamasaki*
}

Research Institute for Global Change, Japan Agency for Marine-Earth Science and Technology, Yokohama, Japan

\begin{abstract}
This paper describes results from numerical experiments which have been made toward a better understanding of tropical cyclone formation. This study uses a nonhydrostatic version of the author's mesoscale-convection-resolving model that was developed in the 1980 s to improve paramerization schemes of moist convection. In this study the horizontal grid size is taken to be $20 \mathrm{~km}$ in an area of $6,000 \mathrm{~km} \mathrm{x} \mathrm{3,000} \mathrm{km,} \mathrm{and} \mathrm{a} \mathrm{non-uniform} \mathrm{coarse} \mathrm{grid} \mathrm{is} \mathrm{used} \mathrm{in} \mathrm{two}$ areas to its north and south.

Results from two numerical experiments are presented; one (case 1) without any environmental flow, and the other (case 2) with an easterly flow without low-level vertical shear. Three circular buoyancy perturbations are placed in the west-east direction at the initial time. Convection is initiated in the imposed latently unstable (positive CAPE) area. In both cases, a vortex with a pressure low is formed, and two band-shaped convective systems are formed to the north and the south of the vortex center. The vortex and two convective systems are oriented in the westsouthwest - eastnortheast direction, and their horizontal scales are nearly $2,000 \mathrm{~km}$.

In case 1, the band-shaped convective system on the southern side is stronger, and winds are stronger just to its south. In contrast, in case 2 , the northern convective system is stronger, and winds are stronger just to its north. Therefore, the distributions of the equivalent potential temperature in the boundary layer and latent instability (positive buoyancy of the rising air) are also quite different between cases 1 and 2. The TC formation processes in these different cases are discussed, with an emphasis on the importance of examining the time change of latent instability field.
\end{abstract}

Keywords: Buoyancy, frictional flow, latent instability, mesoscale-convection-resolving model, mesoscale organized convection, nonhydrostatic model, rainbands, tropical cyclone formation.

\section{INTRODUCTION}

This paper describes results from a study which has been made toward a better understanding of tropical cyclone (TC) ${ }^{1}$ formation. Its better understanding is important with respect to not only the forecast of individual TCs but also reasonable prediction of the global warming effect on TCs.

Our understanding of TC formation has been advanced by a number of observational, theoretical, and numerical studies in these 50 years. However, it appears that TC researchers have, more or less, different views. In particular, the present author's view is different from some (probably many) of TC researchers. Although the main objective of this paper is to describe an understanding based on the results from numerical experiments of TC formation under an idealized (simplified) condition, the author's view, which

\footnotetext{
*Address correspondence to this author at the Research Institute for Global Change, Japan Agency for Marine-Earth Science and Technology, 3173-25 Showa-machi, Kanazawa-ku, Yokohama 236-0001, Japan;

Tel: 81-45-778-5553; Fax: 81-45-778-5706;

E-mail: yamas@jamstec.go.jp
}

${ }^{\S}$ Presented at the 2008 fall and 2009 spring meetings of the Meteorological Society of Japan.

${ }^{1}$ In this paper, the term TC is defined as a tropical vortex in which the maximum wind speed is larger than about $17 \mathrm{~ms}^{-1}$. has not been understood (or not referred to), particularly in these ten years, is emphasized in this paper, based on his studies in these 40 years.

The author's view on TC formation was presented at the second International Workshop on Tropical Cyclones (IWTC) in 1989 as a rapporteur report (Yamasaki [1]). His view has not been essentially modified since that time, as described in a recent review of Yamasaki [2], except that he did not notice, in the 1980s, TC formation from the midtropospheric mesoscale convective vortex (MCV). One of the most important aspects of the view was concerned with the role of surface friction (friction between the sea surface and the atmosphere). Since the CISK concept of Ooyama [3] and Charney and Eliassen [4] proposed in the 1960s, the importance of frictional convergence had been recognized not only for the development but also formation (genesis) of TCs (e.g., Charney and Eliassen [4]; Gray [5]). On the other hand, based on the results from a cumulus-convection ${ }^{2}$ resolving model (CCRM) without parameterization of convection in the 1970s and early 1980s, the author (Yamasaki [6-8]) recognized that not frictional convergence but frictional inflow (or frictional flow) should play an important role in the formation stage of TCs.

\footnotetext{
${ }^{2}$ The term cumulus convection has been used to imply the basic mode of moist convection, at least, since the 1950s. The essential property of cumulus convection can be explained by linear theories in the $1960 \mathrm{~s}$, although it is modified by non-linear effects.
} 
Other important aspects of the view were (1) recognition that it is important to resolve cumulus convection or mesoscale organized convection in a numerical model, without parameterizing the whole effects of moist convection, and (2) recognition that cooling due to evaporation of rainwater in the subcloud layer plays an important role not only in mesoscale organization of cumulus convection but also in successive formation of mesoscale organized convection. The effect of evaporative cooling is not essential to frictional convergence CISK, but frictional inflow CISK which is very important to TC formation. These were also recognized from the studies with the CCRM [6-8].

In the early 1980s, numerical experiments of TC formation were performed by Kurihara and Tuleya [9] and Tuleya and Kurihara [10]. As mentioned above, the author had recognized the importance of explicit treatment of cumulus convection or mesoscale organized convection, in order to simulate and understand TC formation properly. Ooyama [11], who had accepted the author's results in the 1970 s, also expressed a similar view; by stating "We must be very careful not to play the game with loaded dice". Since it was difficult to resolve cumulus convection by a threedimensional numerical model in the 1980s, the author (Yamasaki [12, 13]) developed a model that intended to resolve mesoscale organized convection and treat (parameterize) only the effects of cumulus convection as the subgrid-scale. The model of this type has been referred to as mesoscale-convection-resolving model (MCRM). The author's studies (Yamasaki $[14,15]$ ) on TC formation under idealized conditions with the MCRM as well as his basic studies with the CCRM were important basis for the author's view (Yamasaki [1]).

In the numerical experiments mentioned above, TCs were formed in areas of the latently unstable ${ }^{3}$ atmosphere. Since water vapor is consumed by convection, and latent instability becomes weak or vanishes if the latent and sensible heat is not supplied from the sea surface, the surface heat flux is one of necessary conditions for TC formation. The author has considered the so-called wind-induced surface heat exchange (WISHE), the importance of which was emphasized by Rottuno and Emanuel [16], as one of the important components of frictional convergence CISK of Ooyama [3] and frictional inflow CISK of Yamasaki [1, 2, 8, 12].

Another important aspect of the numerical experiments (Yamasaki $[14,15])$ is the recognition that mesoscale organized convection (abbreviated to MC, mesoscale convection) can be considered as the basic organized form of cumulus convection (Yamasaki [8, 12]), and a TC has a hierarchical structure of convection; that is, cumulus convection, $\mathrm{MC}$, and an ensemble of $\mathrm{MCs}$ that can be referred to as mesoscale convective system (MCS). The typical lifetime of each MC is about 3 hours, but it takes a wide range from a few hours to even 10 hours, depending on

\footnotetext{
${ }^{3}$ The term 'latently unstable' and 'latent instability' refer to the instability of the atmosphere in which the rising air has positive buoyancy in the conditionally unstable stratification. This term has been used, at least, since the 1950s. It should be remarked that the instability related to the term CAPE (convective available potential energy), which has been used by many researchers in these 30 years, means the same instability.
}

the intensity of frictional flow, the low-level vertical shear and other conditions. MCS corresponds to a band-shaped convective system (or a rainband) in many cases, and it consists of a few or several MCs. In other words, MCs are constituents of MCS such as rainbands (and mesoscale cloud clusters). Although the existence of mesosale echo cells in spiral rainbands were already noticed from radar observations in the 1950 s and the 1960 s, a clear recognition that there exists a basic organized form (MC) of cumulus convection was obtained from the author's studies with the CCRM in the 1980s. Even in recent years, many of TC researchers have considered that a rainband consists of cumulus convection; MC has not necessarily been recognized as one of the important hierarchical structures of convection in TCs. The author's recognition of the importance of MC in the 1980s was a basis for development of the MCRM [12,13]. That is, this recognition led the author to have the idea that MC should be resolved by a numerical model, only the effects of cumulus convection being implicitly treated (or parameterized), without using such a parameterization of the whole effects of moist convection as done by other researchers $[9,10]$ in the early 1980s.

Nnumerical experiments with the MCRM were also performed in the 2000s (Yamasaki [17, 18]) with an improved version of the MCRM (Yamasaki [19]). Two examples of TC formation cases were presented among a number of cases, which were obtained from a long-period time integration of the MCRM under idealized (simplified) conditions in which mid-latitude baroclinic waves and the subtropical high were taken into consideration. These studies described two cases in which one or two MCSs among many MCSs played an important role in TC formation. A comment on the relation between the author's past studies and other researchers' studies (e.g., Hendricks et al. [20]) was also given in Yamasaki [17].

The MCRM used in the author's studies mentioned above was a hydrostatic model because most of TC models, numerical weather prediction models, and general circulation models had used the hydrostatic assumption in the 1980s when the MCRM was first developed [12, 13]. Recently the author developed a nonhydrostatic version of the MCRM (Yamasaki [21]), incorporating the author's scheme used in the hydrostatic MCRM [12, 19] into a three-dimensional nonhydrostatic model (CCRM) of Yamasaki [22]. Although the present paper describes results from numerical experiments with the nonhydrostatic MCRM, it does not mean that the hydrostatic MCRM is not appropriate. It should be emphasized that the hydrostatic MCRM is still very important because it requires much less computer time. The hydrostatic MCRM has also been used in the author's study on the Madden-Julian oscillation (Yamasaki [23]) as well as TCs and cloud clusters associated with Baiu/Meiyu fronts (e.g., Yamasaki [24]). It is important that the MCRM can be appropriately applied to not only TCs but also many other phenomena in which moist convection plays an important role.

As is well known, TC formation processes in the real atmosphere have a wide variety. This study intends to understand only some aspects of various TC formation processes, using simplified (idealized) initial conditions. 
That is, this study is a step toward better (and satisfactory) understanding of various TC formation processes. In this study we deal with, among various TC formation processes, the case in which a TC forms from mesoscale convective systems (MCSs) in a large-scale (synoptic-scale) vortex with a horizontal scale of about 2,000 km. The author's primary concern is the distribution and behavior of convection in TC formation processes, as it has been since his studies [14, 15].

\section{MODEL AND EXPERIMENTAL DESIGN}

This study is an extension of the author's studies on TC formation with the hydrostatic MCRM [14, 15, 17, 18]. As mentioned in Section 1, the nonhydrostatic version (Yamasaki [21]) is used in this study. Although the differences between results from the hydrostatic and nonhydrostatic MCRMs are not essential to better understanding of TC formation in view of the present status of our understanding, studies with the nonhydrostatic MCRM are also necessary. It is important that results from the nonhydrostatic MCRM can be compared with those from the CCRM (grid size of $1 \mathrm{~km}$ or less), in the same dynamical and thermodynamical model frameworks and numerical schemes, although such comparison remains to be made in the future partly because of the present computer restrictions.

As mentioned in Section 1, in this study, we deal with the case in which a TC forms from mesoscale convective systems (MCSs) in a large-scale vortex with a horizontal scale of about $2,000 \mathrm{~km}$. In order to obtain such a vortex, three circular buoyancy perturbations are given in the lower layer $(0<\mathrm{z}<2.5 \mathrm{~km})$ at an interval of $800 \mathrm{~km}$ in the westeast direction at the initial time. The radius of each perturbation is taken to be $100 \mathrm{~km}$, and its maximum temperature anomaly is $1 \mathrm{~K}$ at a height of $1.25 \mathrm{~km}$ (with a horizontal profile of the square of cosine).

Results from two numerical experiments are presented in this paper. In case 1, any environmental flow such as the trade easterlies is not imposed. In case 2, an environmental easterly flow of $5 \mathrm{~ms}^{-1}$ is given in a latitudinal belt of 2,000 $\mathrm{km}(-1,000 \mathrm{~km}<\mathrm{y}<1,000 \mathrm{~km})$ at the initial time. (The origin of $y$ is taken to be $15 \mathrm{~N}$.) This easterly flow of $5 \mathrm{~ms}^{-1}$ is confined to a layer below a $7.5 \mathrm{~km}$ height, and it is taken to be 0 above $15 \mathrm{~km}$. In the northern and southern areas (y > $2,000 \mathrm{~km}$ and $\mathrm{y}<-2,000 \mathrm{~km}$ ), no environmental flow is given. Under this specification for case 2, the horizontal shear exists outside the TC formation area, whereas vertical shear exists only in the middle and upper troposphere in the TC formation area at the initial time. However, the vertical shear given in case 2 is not considered important. It is known that low-level vertical shear is favorable to mesoscale organization of cumulus convection in many cases, whereas strong vertical shear is unfavorable to TC formation (e.g., Gray [5]). Results from studies on the effects of the vertical shear on convective activity in TC formation processes remain to be reported in the future. The subtropical high and other disturbances are not taken into consideration in this study. (These were included in the previous studies $[17,18]$, which should be extended in the future.) As evident from the difference between cases 1 and 2 , it is one of the objectives of this study to clarify the effects of the environmental easterly flow without low-level vertical shear (that is, the effects of the surface heat flux enhanced by surface easterly flow) on TC formation.

The vertical profile of the environmental temperature used in this study is shown in Table 1. This vertical profile nearly corresponds to that of the tropical northwestern Pacific in the summer season. In this study, a 30-layer model is used. The heights shown in the Table indicate levels where vertical velocity is predicted. Thermodynamic variables, horizontal velocity and pressure are predicted between these levels. That is, Lorenz-type grid is used (instead of CharneyPhillips grid used in the hydrostatic MCRM). The vertical profile of the initial relative humidity at $(x=0, y=0)$ is also shown in Table 1. The relative humidity is reduced to $80 \%$ of these values at $y=1,000 \mathrm{~km}, \mathrm{y}=-2,000 \mathrm{~km}, \mathrm{x}=3,000 \mathrm{~km}$ and $\mathrm{x}=-3,000 \mathrm{~km}$, with the horizontal profile of the square of cosine in the $\mathrm{x}$ - and $\mathrm{y}$ - directions. The latitudinal distribution of the sea surface temperature (SST) used in this study is shown in Table 2 . The SST between the latitudes indicated in this Table is linearly interpolated. The SST to the norh of $35 \mathrm{~N}$ and to the south of $5 \mathrm{~S}$ is taken to be uniform.

The computational domain is taken to be $6,000 \mathrm{~km}$ in the west-east direction, and $5,000 \mathrm{~km}$ in the north-south direction. The horizontal grid size is taken to be $20 \mathrm{~km}$ in the central belt $(-1,500 \mathrm{~km}<\mathrm{y}<1,500 \mathrm{~km})$, and a non-uniform coarse grid is used in the northern and southern areas. The cyclic condition is used in the west-east direction, and the closed boundary condition is used in the northern and

Table 1. The Environmental Temperature $T_{B}$ Specified for a 30-Layer Model. The Heights of the Levels where the Vertical Velocity is Predicted and the Initial Relative Humidity at the Center of the Area $R_{H 0}$ are Also Shown

\begin{tabular}{|c|c|c|c|c|c|}
\hline $\mathbf{z}(\mathbf{k m})$ & $\boldsymbol{T}_{\boldsymbol{B}}(\mathbf{K})$ & $\boldsymbol{R}_{\boldsymbol{H} \boldsymbol{0}}(\boldsymbol{\%})$ & $\mathbf{z}(\mathbf{k m})$ & $\boldsymbol{T}_{\boldsymbol{B}}(\mathbf{K})$ & $\boldsymbol{R}_{\boldsymbol{H} \mathbf{0}}(\boldsymbol{\%})$ \\
\hline \hline 27.0 & 215.0 & 30 & 7.0 & 259.4 & 78 \\
\hline 23.9 & 215.0 & 33 & 6.5 & 262.5 & 80 \\
\hline 21.3 & 212.0 & 36 & 6.0 & 265.5 & 82 \\
\hline 19.1 & 206.0 & 39 & 5.5 & 268.4 & 83 \\
\hline 17.2 & 200.0 & 42 & 5.0 & 271.3 & 84 \\
\hline 15.6 & 200.4 & 45 & 4.5 & 274.1 & 85 \\
\hline 14.2 & 205.9 & 48 & 4.0 & 276.8 & 86 \\
\hline 13.0 & 214.2 & 51 & 3.5 & 279.4 & 87 \\
\hline 12.0 & 221.9 & 54 & 3.0 & 282.0 & 88 \\
\hline 11.1 & 229.0 & 57 & 2.5 & 284.6 & 89 \\
\hline 10.3 & 235.5 & 60 & 2.0 & 287.2 & 90 \\
\hline 9.6 & 241.1 & 63 & 1.5 & 289.9 & 92 \\
\hline 9.0 & 245.9 & 66 & 1.0 & 292.6 & 94 \\
\hline 8.5 & 249.4 & 69 & 0.5 & 296.0 & 89 \\
\hline 8.0 & 252.8 & 72 & 0.0 & 300.0 & 83 \\
\hline 7.5 & 256.1 & 75 & & & \\
\hline & & & & & \\
\hline
\end{tabular}




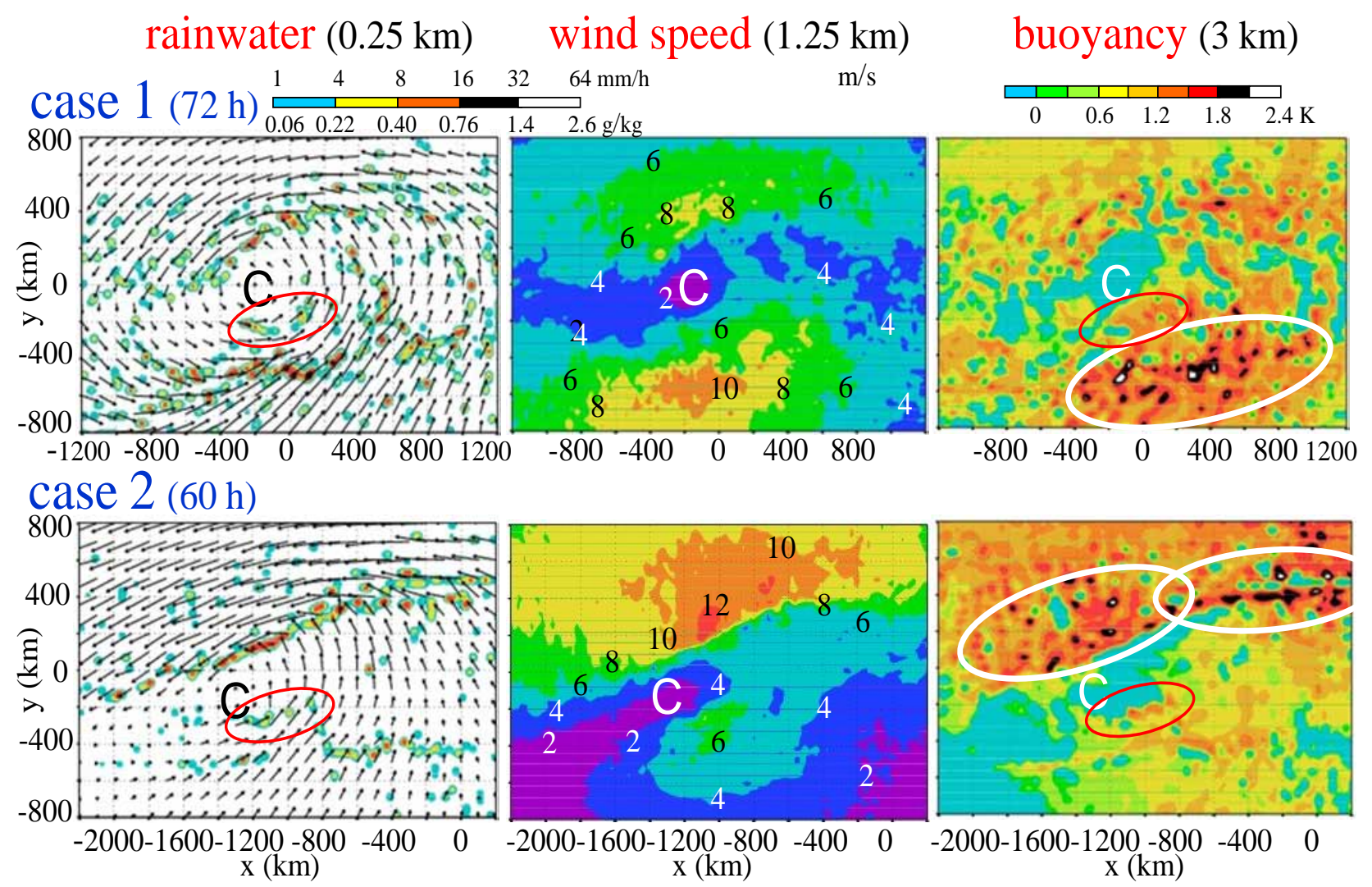

Fig. (1). Mixing ratio of rainwater at the lowest level of the model $(0.25 \mathrm{~km})$, wind speed at $1.25 \mathrm{~km})$, and a measure of buoyancy of rising air, at $72 \mathrm{~h}$ in case 1 (upper panels), and at $60 \mathrm{~h}$ in case 2 (lower panels). The letter $\mathrm{C}$ indicates the location of the vortex center. The red ellipse indicates an area of convection located just to the southeast of the vortex center. The white ellipse indicates an area of strong buoyancy (latent instability).

southern boundaries. The MCRM is designed so that a grid size of $5-20 \mathrm{~km}$ can be used. Although it can be used even for a grid size smaller than $5 \mathrm{~km}$ because the effects of cumulus convection are parameterized, it can be used more efficiently for a grid size of about $5 \mathrm{~km}$. In order to save computer time or to understand the TC formation efficiently, a $20-\mathrm{km}$ grid is used in this study, as done in the previous studies [17, 18]. The MCRM with this grid size will be desirable for studies of the global warming effect on TCs when the grid size of climate models becomes about $20 \mathrm{~km}$, although most of the present climate models still have larger grid sizes. This study as well as $[17,18]$ should be a basis for the global warming studies with the MCRM in the future.

Table 2. Latitudinal Distribution of the Sea Surface Temperature Used in the Numerical Experiments

\begin{tabular}{|c|c|}
\hline Latitude & SST \\
\hline \hline $35 \mathrm{~N}$ & 296.0 \\
\hline $30 \mathrm{~N}$ & 299.0 \\
\hline $25 \mathrm{~N}$ & 301.0 \\
\hline $20 \mathrm{~N}$ & 302.0 \\
\hline $10 \mathrm{~N}$ & 302.0 \\
\hline $5 \mathrm{~N}$ & 301.0 \\
\hline $\mathrm{EQ}$ & 300.0 \\
\hline $5 \mathrm{~S}$ & 298.0 \\
\hline
\end{tabular}

\section{RESULTS}

As mentioned in Section 2, three buoyancy perturbations are given in a non-uniform relative humidity field at the initial time. Each perturbation produces ring-shaped convection, which propagates outward (expands). The three ring-shaped convective systems merge eventually. As a result, two band-shaped convective systems, which are oriented in the westsouthwest - eastnortheast direction, are produced. The left panels in Fig. (1) show the rainwater mixing ratio at the lowest level of the model (at a height of $250 \mathrm{~m}$ ) at $72 \mathrm{~h}$ in case 1 and $60 \mathrm{~h}$ in case 2 . The southern convection is more intense in case 1 , whereas the northern convection is more intense in case 2 . These panels also show wind fields at $750 \mathrm{~m}$. A large-scale (synoptic-scale) vortex, which is oriented in the same direction as the band-shaped convection, can be seen. Its longitudinal scale is about 2,000 $\mathrm{km}$. The center of the vortex is indicated by C. Large horizontal shear and vorticity can be seen around the northern band in case 2 .

The middle panels in Fig. (1) show the wind speed at 1.2 $\mathrm{km}$. The wind is stronger in the southern and northern areas in cases 1 and 2, respectively. The former feature is due to the effect of the latitudinal variation of the Coriolis parameter, and the latter is due to superposition of the environmental easterly flow and the wind associated with the vortex.

The right panels show a measure of buoyancy that the air rising from the boundary layer (at $750 \mathrm{~m}$ ) acquires at $3 \mathrm{~km}$. 


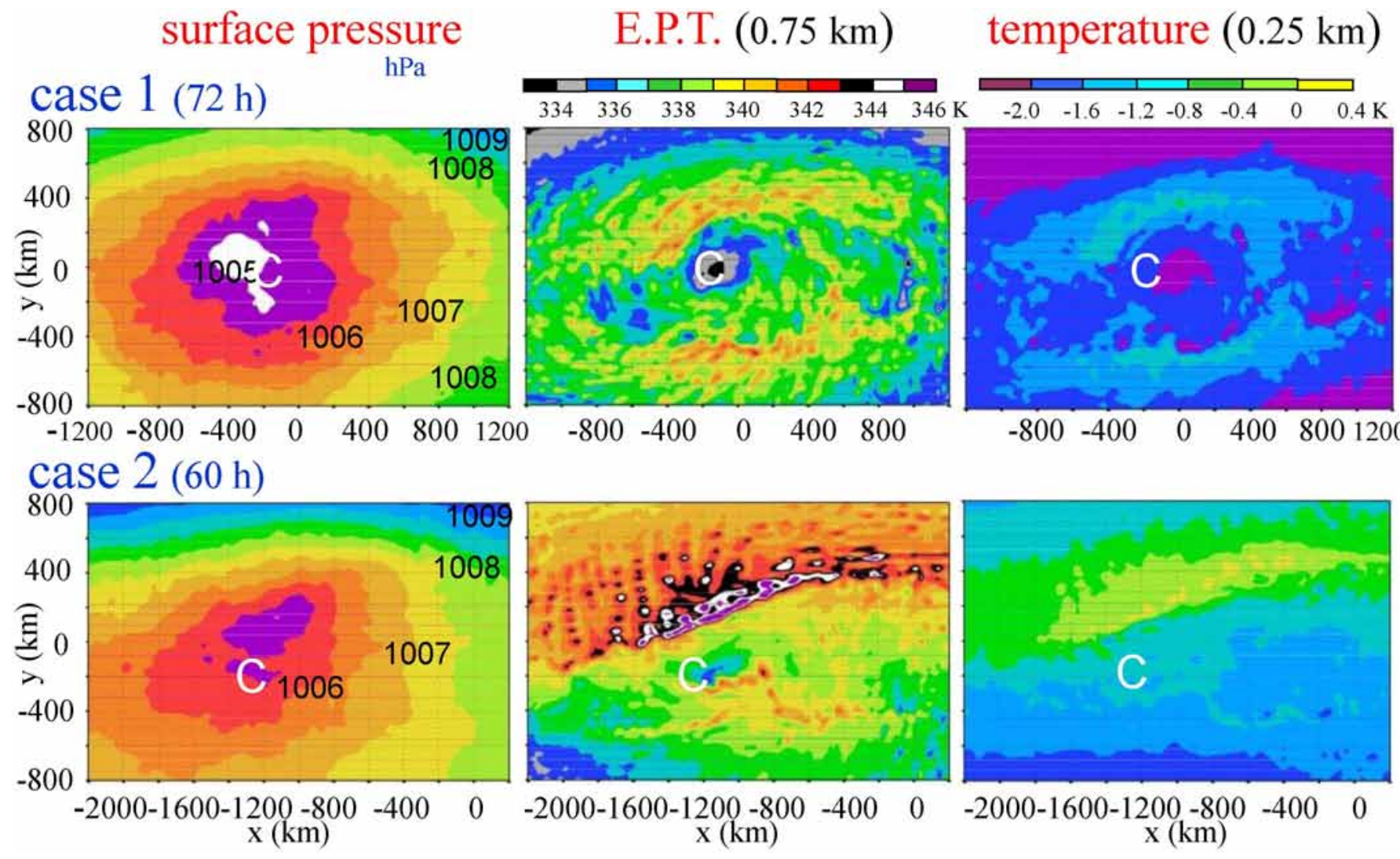

Fig. (2). Surface pressure, equivalent potential temperature at $0.75 \mathrm{~km}$, and temperature deviation from the basic state at the lowest level of the model, at $72 \mathrm{~h}$ in case 1 (upper panels), and at $60 \mathrm{~h}$ in case 2 (lower panels), corresponding to Fig. (1).

It is not represented by buoyancy force but by the difference between the rising air and the surrounding air (effect of drag force of rainwater included), in the temperature unit. Although the vertical distribution of the buoyancy is important, the author has, in these 25 years, presented the buoyancy at $3 \mathrm{~km}$ when only one physical quantity is presented. It should also be remarked that the author has been more interested in this quantity than CAPE (convective available potential energy, vertically integrated energy produced by buoyancy). The right panels indicate that the buoyancy (latent instability indicated by positive buoyancy) is larger to the south of the southern convection and to the north of the northern convection in cases 1 and 2, respectively. This is due to the surface (latent and sensible) heat flux enhanced by stronger surface winds. It can also be seen that an area of the vortex center is latently stable (indicated by blue color).

It is important to note that convection also occurs to the southeast of the vortex center in both cases (red ellipse in left panels). This area is latently unstable, as shown in the right panels. Corresponding to such convection, the wind has begun to intensify in this area. Although the wind speed in case 2 is only 4-6 ms ${ }^{-1}$, the southwesterly flow of latently unstable air and resulting convection play an important role in tropical cyclone (TC) formation, as shown later. As mentioned in Section 1, this study deals with TC formation associated with a synoptic-scale vortex, and only one case among many TC formation processes which occur with various features (such as an inverted V-shaped cloud cluster) in the real tropics.
Fig. (2) shows surface pressure, equivalent potential temperature in the boundary layer (at a height of $750 \mathrm{~m}$ ), and temperature deviation $(250 \mathrm{~m})$ from the basic state (environment temperature, 298K, Table 1) in cases 1 and 2, corresponding to Fig. (1). The central surface pressure is about $1,005 \mathrm{hPa}$ in both cases. The equivalent potential temperature in the boundary layer is higher around the bandshaped convection in both cases. In case 2, it is much higher around and to the north of the northern convection. This feature corresponds to that for buoyancy at $3 \mathrm{~km}$ (right panels in Fig. 1). The temperature near the surface in case 2 is higher in a strong wind area around and to the north of the northern convection. Comparison of the temperatures in cases 1 and 2 indicates that the temperature is generally lower in case 1. It is lower than the basic state temperature in the whole area, which depends on the choice of the basic state (relative to the sea surface temperature). Since the environmental easterly flow is included in case 2 , as in the real tropics, the temperature deviation is smaller than in case 1.

In the following, we will see how convection behaves in the TC formation process. Fig. (3) shows the mixing ratio of rainwater at $250 \mathrm{~m}$ (or the surface rainfall intensity), which is a good measure of convective activity. The result for case 1 is shown at a time interval of 6 hours for $72-120 \mathrm{~h}$. The area shown is taken to be much smaller than that in Fig. (1) to show the behavior of convection clearly. Fig. (4) shows the mixing ratio at a time interval of 4 hours for $124-144 \mathrm{~h}$, and $150 \mathrm{~h}, 156 \mathrm{~h}$, and $168 \mathrm{~h}$. The area shown is different from that in Fig. (3). The central surface pressure (red numerals) and 


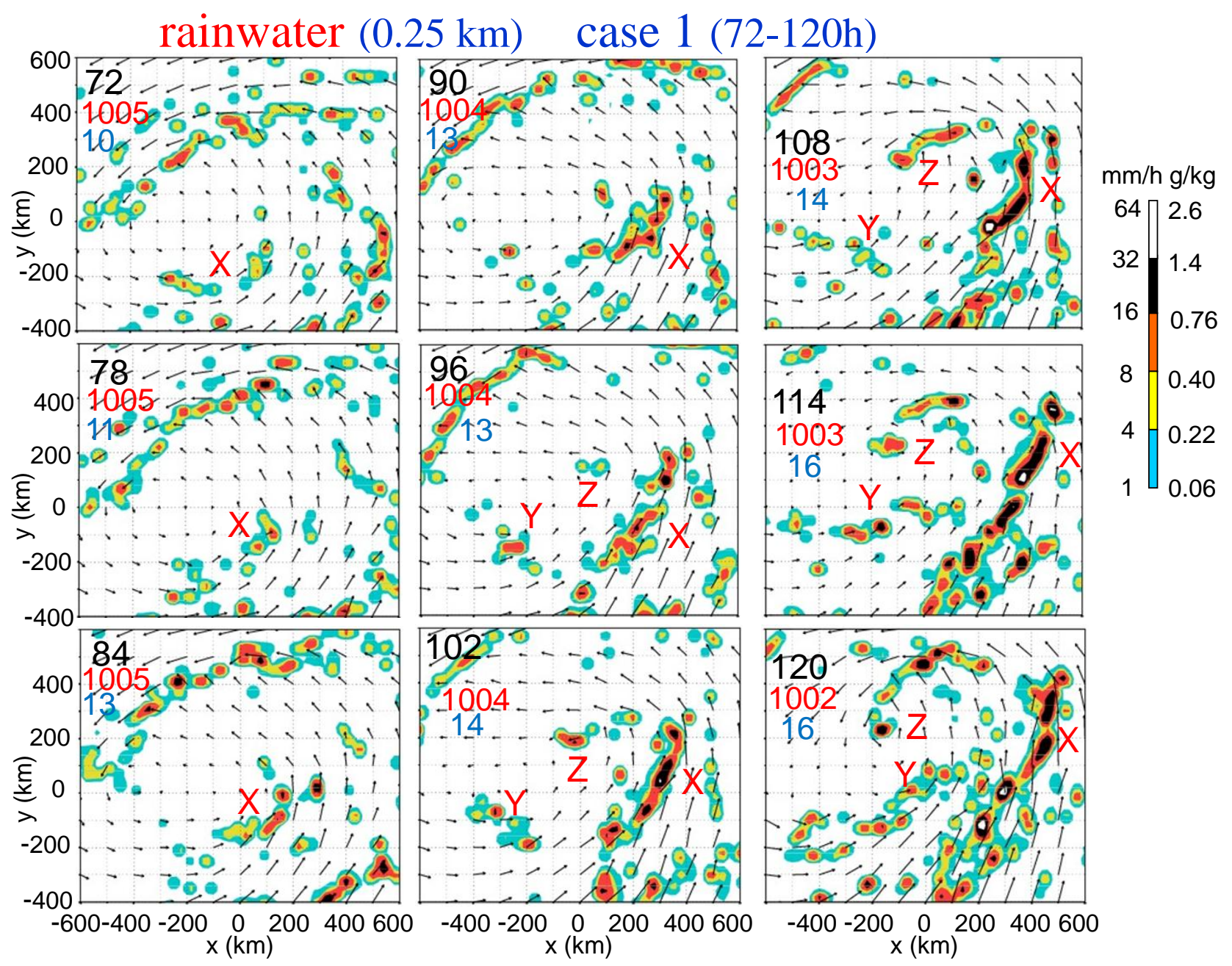

Fig. (3). Rainwater mixing ratio at the lowest level of the model (or surface rainfall intensity) at a time interval of 6 hours from $72 \mathrm{~h}$ to $120 \mathrm{~h}$ in case 1 . Three major convective systems (rainbands) are indicated by X, Y, and Z. The central surface pressure (hPa) and the maximum wind speed at $1.25 \mathrm{~km}\left(\mathrm{~ms}^{-1}\right)$ are indicated by numerals.

the maximum wind speed at $1.2 \mathrm{~km}$ (blue numerals) are also shown in each panel. In this paper, the TC formation time is defined as the stage when the wind speeds exceed $17 \mathrm{~m} / \mathrm{s}$ in somewhat wide area. Although the determination of the TC formation time has uncertainty under this definition, $136 \mathrm{~h}$ can be considered as the TC formation time.

Many different behaviors of convection can occur even in numerical models as well as in nature. The behavior shown in Figs. $(\mathbf{3}, \mathbf{4})$ is an example among many cases of TC formation processes. The TC in case 1 forms from a cloud cluster associated with a synoptic-scale vortex in the absence of the environmental easterly flow. It can be seen from Figs. $(3,4)$ that 'three' major convective systems (mesoscale convective systems MCSs with band-shape, or rainbands) play an important role in TC formation. One is MCS X, which is located to the southeast of the vortex center at $72 \mathrm{~h}$ (Fig. 1). It moves northeastward, while it grows and becomes longer. The second is MCS Y, which forms to the west of MCS X before 96h, grows, and enters in the inner area of the vortex (on the inner side of MCS X, closer to the vortex center). At this stage (after 114h), MCS Y becomes the primary convective system that contributes to the deepening of the central surface pressure (vortex intensification). The third is MCS Z, which forms to the north of the vortex center before $96 \mathrm{~h}$, grows, and moves to the west of the vortex center (extends cyclonically, as MCSs X and Y). This feature can be generally seen as the cyclonic intrusion of the head of the major rainband (such as MCS X) into the central area of the vortex in numerical models and in nature. MCS Z plays an important role in rapid deepening of the central surface pressure and eye formation at the later stage (after $168 \mathrm{~h}$, not shown).

It can be speculated that MCSs $\mathrm{X}, \mathrm{Y}$, and $\mathrm{Z}$ cannot be identified for such a long period of time as seen in case 1 , if a fine-resolution model (CCRM) is used. These MCSs are probably replaced by new MCSs that form in their vicinity. However, gross features in case 1 are probably obtained even in a fine-resolution model, as in nature.

Fig. (5) shows several fields at $96 \mathrm{~h}$ when the maximum wind speed is still $12 \mathrm{~ms}^{-1}$ (upper middle panel). The area shown is the same as that in Figs. $(\mathbf{1}, \mathbf{2})$. The central surface pressure is $1,004 \mathrm{hPa}$ (lower middle). The low-level rainwater field (lower left) indicates that the two convective systems are oriented in the southwest - northeast direction 


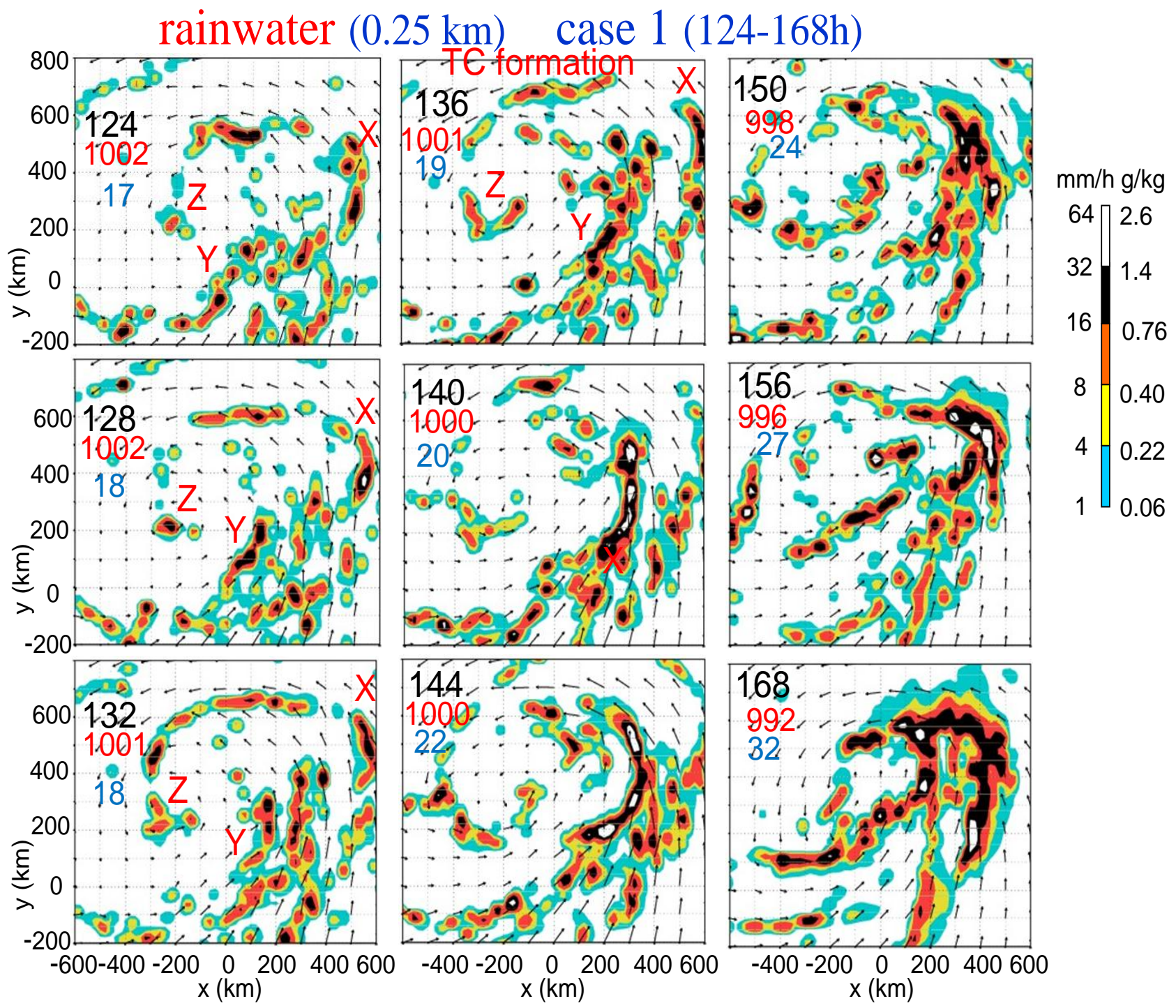

Fig. (4). Same as Fig. (3) but at a time interval of 4 hours from $124 \mathrm{~h}$ to $144 \mathrm{~h}$, and 150h, 156h, and $168 \mathrm{~h}$.

and that convective activity just to the southeast of the vortex center becomes much stronger at this stage than at $72 \mathrm{~h}$ (upper left of Fig. 1). The wind speed at $1.2 \mathrm{~km}$ indicates that the wind is strongest to the southeast of the vortex center. This feature, which is seen in TC formation process in the absence of the environmental easterly flow, is due to the effect of the latitudinal variation of the Coriolis parameter. Cloud ice in the upper troposphere (upper left) occupies a wide area of the southern portion of the area shown. Since the upper-tropospheric flow has northerly component to the east southeast of the vortex center, the upper-tropospheric ice cloud is mostly located to the south of the southern convective band. The area of the vortex center is still latently stable (negative buoyancy, upper right). The equivalent potential temperature in the boundary layer $\theta_{e}^{B}$ (lower right) is very low in the central area, as it is at $72 \mathrm{~h}$ (upper middle of Fig. 2). Buoyancy at $3 \mathrm{~km}$ and $\theta_{e}^{B}$ have become higher in the large portion of the outer area at this stage (due to the surface heat flux associated with the vortex flow).

Fig. (6) shows the results at $136 \mathrm{~h}$ (TC formation stage). The central surface pressure at this stage is about $1,001 \mathrm{hPa}$. In the usual case of TC formation, the central pressure is about $1,004 \mathrm{hPa}$ in many cases. Since the horizontal scale of the TC in the present case is very large, the surface pressure at the TC formation stage is significantly lower. The wind speed fields at $1.2 \mathrm{~km}$ (upper middle) indicates that the maximum wind is located at a large distance (about $400 \mathrm{~km}$ ) from the vortex center. This distance is probably too large compared with observed TCs, even with very large TCs. This somewhat unrealistic feature is due to the absence of the environmental easterly flow and/or the initial condition of buoyancy perturbations. At the later stage, convective activity in the central area of the TC becomes stronger. The location of the maximum wind approaches the vortex center, and an eye and eyewall are formed eventually (not shown). It 


\section{case $1(96 \mathrm{~h})$ cloud ice $(7.5-12 \mathrm{~km})$}

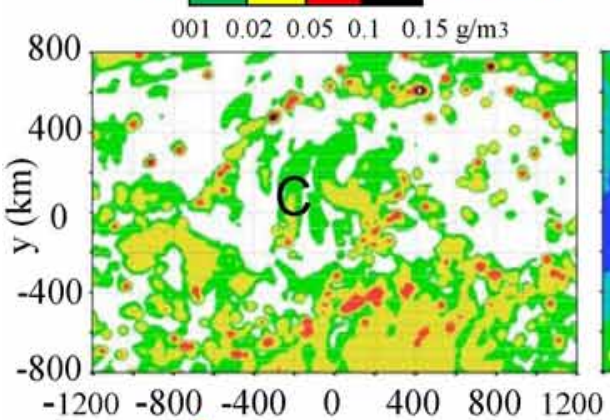

$\begin{array}{lllllll}-1200 & -800 & -400 & 0 & 400 & 800 & 1200\end{array}$ rainwater $(0.25 \mathrm{~km})$

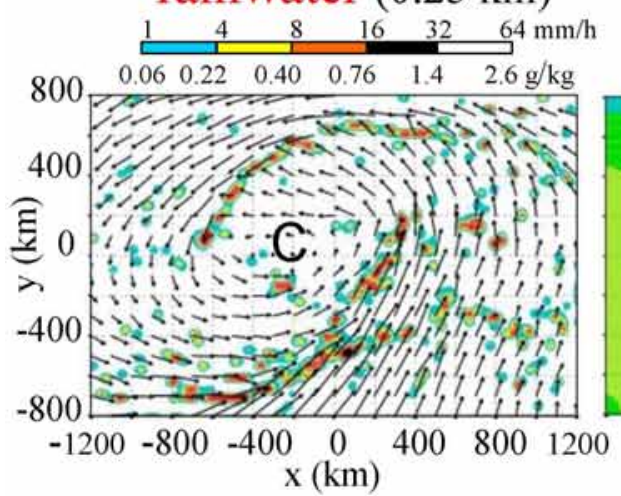

wind speed $(1.25 \mathrm{~km})$ $V_{\max }=12 \mathrm{~m} / \mathrm{s}$

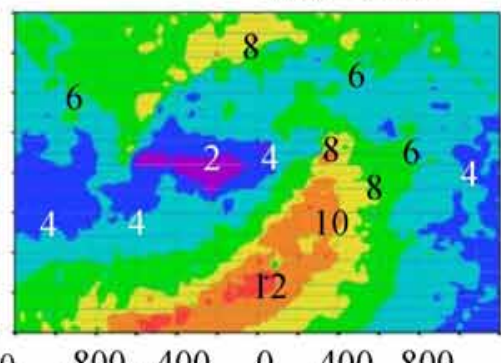

$\begin{array}{lllll}-800 & -400 & 0 & 400 & 800\end{array}$

surface pressure

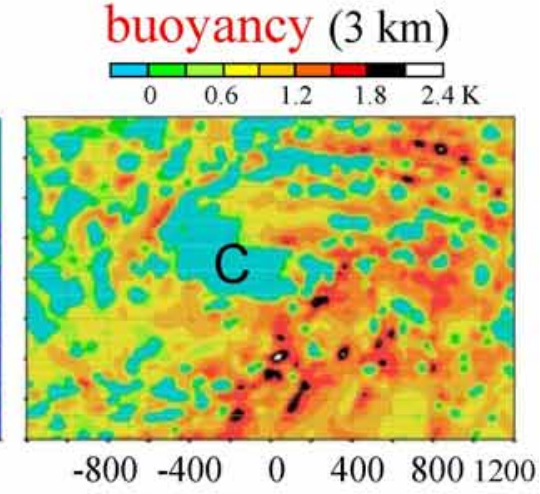

E.P.T. $(0.75 \mathrm{~km})$
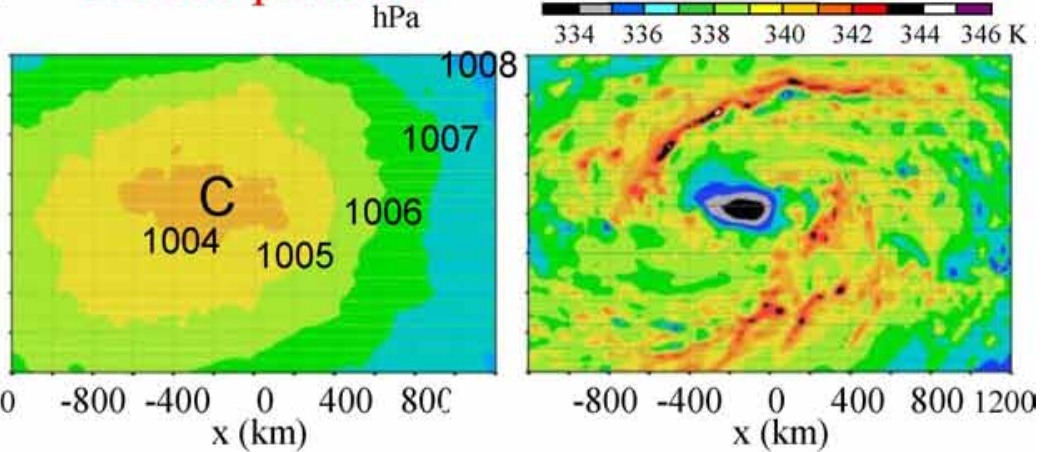

Fig. (5). Several selected fields at $96 \mathrm{~h}$ in case 1 . The mixing ratio of cloud ice in the upper troposphere (7.5-12 km), rainwater mixing ratio at $0.25 \mathrm{~km}$, wind speed at $1.25 \mathrm{~km}$, surface pressure, buoyancy of rising air at $3 \mathrm{~km}$, and equivalent potential temperature at $0.75 \mathrm{~km}$.

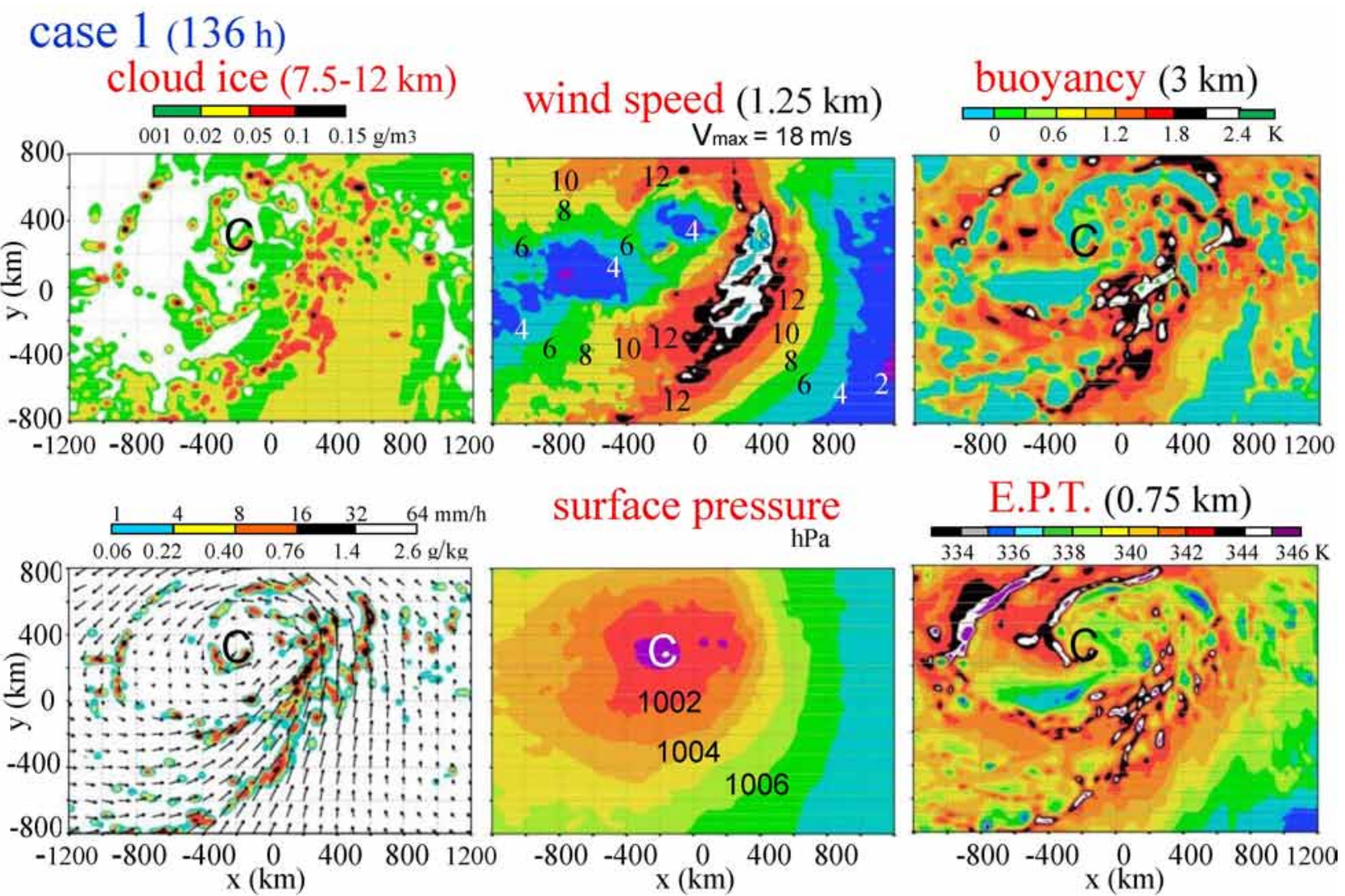

Fig. (6). Same as Fig. (5) but at $136 \mathrm{~h}$. 
case 2
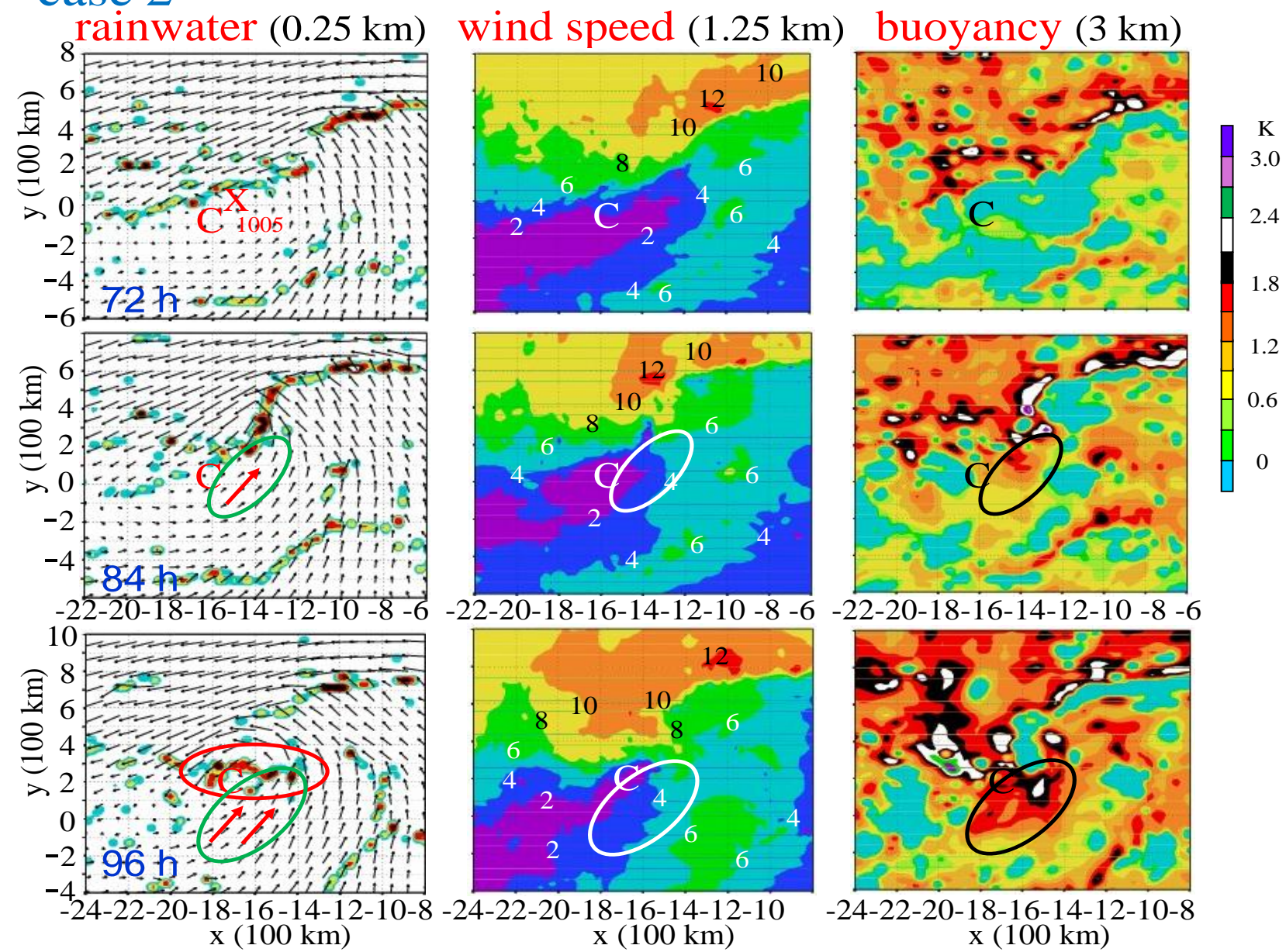

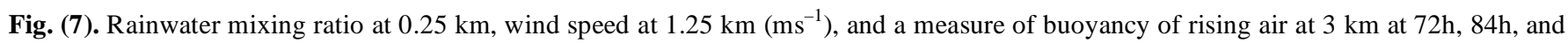
$96 \mathrm{~h}$ in case 2.

should be added that the maximum wind is located to the east-southeast of the vortex center at the TC formation stage, and afterwards, the strong wind area extends to the northeast - north of the vortex center. This area further extends to the west, and contributes to the formation of a nearly axially symmetric TC. Cloud ice in the upper troposphere (upper left) occupies a large portion of the area around and to the southeast of long convective bands located in the eastern southeastern portion of the vortex. Buoyancy in the free atmosphere (upper right) and equivalent potential temperature in the boundary layer $\theta_{e}^{B}$ (lower right) at this (TC formation) stage are significantly larger compared with those at $96 \mathrm{~h}$. Stronger convection corresponds to this feature. Although $\theta_{e}^{B}$ is higher in the northwestern area than in the southeastern area of the vortex center, the buoyancy is stronger in the southeastern area. This is due to asymmetry of the temperature field. The northwestern area is generally warmer in the troposphere than the southeastern area.

Now we proceed to examine the results in case 2. Figs. (7-10) show three fields at a time interval of 12 hours from $72 \mathrm{~h}$ to $156 \mathrm{~h}$, and $162 \mathrm{~h}$ (TC formation stage), and $168 \mathrm{~h}$. The area shown is taken to be much smaller than that in Fig. (1). In addition, the areas shown are different after $96 \mathrm{~h}$ and after 120h. At $72 \mathrm{~h}$, convection still takes a form of two major convective bands. As was mentioned, the northern bandshaped convection as well the southern (left panel) has contributed to the formation of the synoptic-scale vortex and pressure low. As already seen at 60h (lower panels of Fig. 1), it is latently stable (negative buoyancy) to the south of the northern convective band (indicated by blue color in the right panel), and large horizontal shear and vorticity can be seen around the northern band (left and middle panels). Our interest is how convection forms, behaves, and contributes to intensification of the vortex and TC formation.

At $84 \mathrm{~h}$, significantly strong latent instability has appeared just to the east of the vortex center (indicated by black ellipse corresponding to green ellipse in the left panel). The southwesterly flow in this area contributes to formation and growth of convection in the eastern portion of the westeast oriented convective system, which is seen at 96h (red ellipse). (The convective system in the western portion is originally the western portion of the northern band-shaped convection.) The wind is slowly intensified to the southeast of the vortex center by the effects of the convective systems, although the wind speed is still less than $8 \mathrm{~ms}^{-1}$ at $96 \mathrm{~h}$.

At $108 \mathrm{~h}$, a band-shaped convective system, which is oriented in the northeast - southwest direction, forms and 
grows in the southwesterly flow to the southeast of the vortex center. The intensification of the wind is still slow. The wind speed attains nearly $10 \mathrm{~ms}^{-1}$ at $120 \mathrm{~h}$, and $12 \mathrm{~ms}^{-1}$ at $132 \mathrm{~h}$. In the northern area, the wind speed takes a maximum of about $14 \mathrm{~ms}^{-1}$ at $120-132 \mathrm{~h}$. The wind in this area begins to weaken afterwards, although the vortex is intensified.

At $144 \mathrm{~h}$, a new convective system (indicated by purple ellipse) forms in an area close to the vortex center. This convective system becomes the primary system which causes the vortex intensification. It is important to note that the location of the maximum wind is much closer to the vortex center (owing to the new convective system) because its inward shift is important for the central surface pressure to deepen rapidly. Although the central surface pressure is $1,003 \mathrm{hPa}$, the maximum wind speed is $13-14 \mathrm{~ms}^{-1}$, which has not acquired TC intensity. This is because the maximum wind is still located at a large distance (about $200 \mathrm{~km}$ ) from the vortex center. In the northern area of the vortex, the wind has weaken from $14 \mathrm{~ms}^{-1}$ to $10 \mathrm{~ms}^{-1}$.

Although the determination of TC formation time includes some uncertainty, $162 \mathrm{~h}$ can be considered as the TC formation time in case 2 because the area of wind speeds stronger than $17 \mathrm{~ms}^{-1}$ has become large to some extent. The central surface pressure is $1,001 \mathrm{hPa}$, which is lower compared with that in the ordinary-scale TC. It can also be seen that the vortex center (and pressure center) shifts eastward (about $400 \mathrm{~km}$ ) in a period of 144-162h, although the environmental easterly flow exists. This is due to strong convection which is located to the southeast of the vortex center. (This feature is also seen in case 1 in which the easterly flow is not included.) The primary convection is strongly controlled by frictional flow associated with the strong wind. Owing to this convection, the temperature rises, and the surface pressure falls. That is, the pressure field follows the wind field through convective effects, as in a vortex whose scale is smaller than the Rossby deformation radius.

The strong wind area to the southeast of the TC center extends northward after $162 \mathrm{~h}$, and it is connected with the northern area of the strong wind (Fig. 10). Afterwards, it extends to the northwest and the west of the TC center (not shown), and the TC becomes a nearly axially symmetric, very strong TC. Although the vortex center (pressure center) moves eastward in a short period before TC formation (144h-162h), the TC moves westward (precisely, in the westnorthwest direction) in the environmental easterly flow after the TC formation stage.

The $\theta_{e}$ fields in the boundary layer (at a height of $750 \mathrm{~m}$ ) at several selected times are shown in Fig. (11) (The field at $60 \mathrm{~h}$ is shown in the lower middle panel of Fig. 2). The $\theta_{e}$ field should be similar to the buoyancy field at $3 \mathrm{~km}$ (Figs. 7-10) if the temperature at $3 \mathrm{~km}$ is uniform. The northwestern area shown in Fig. (11) continues to have large

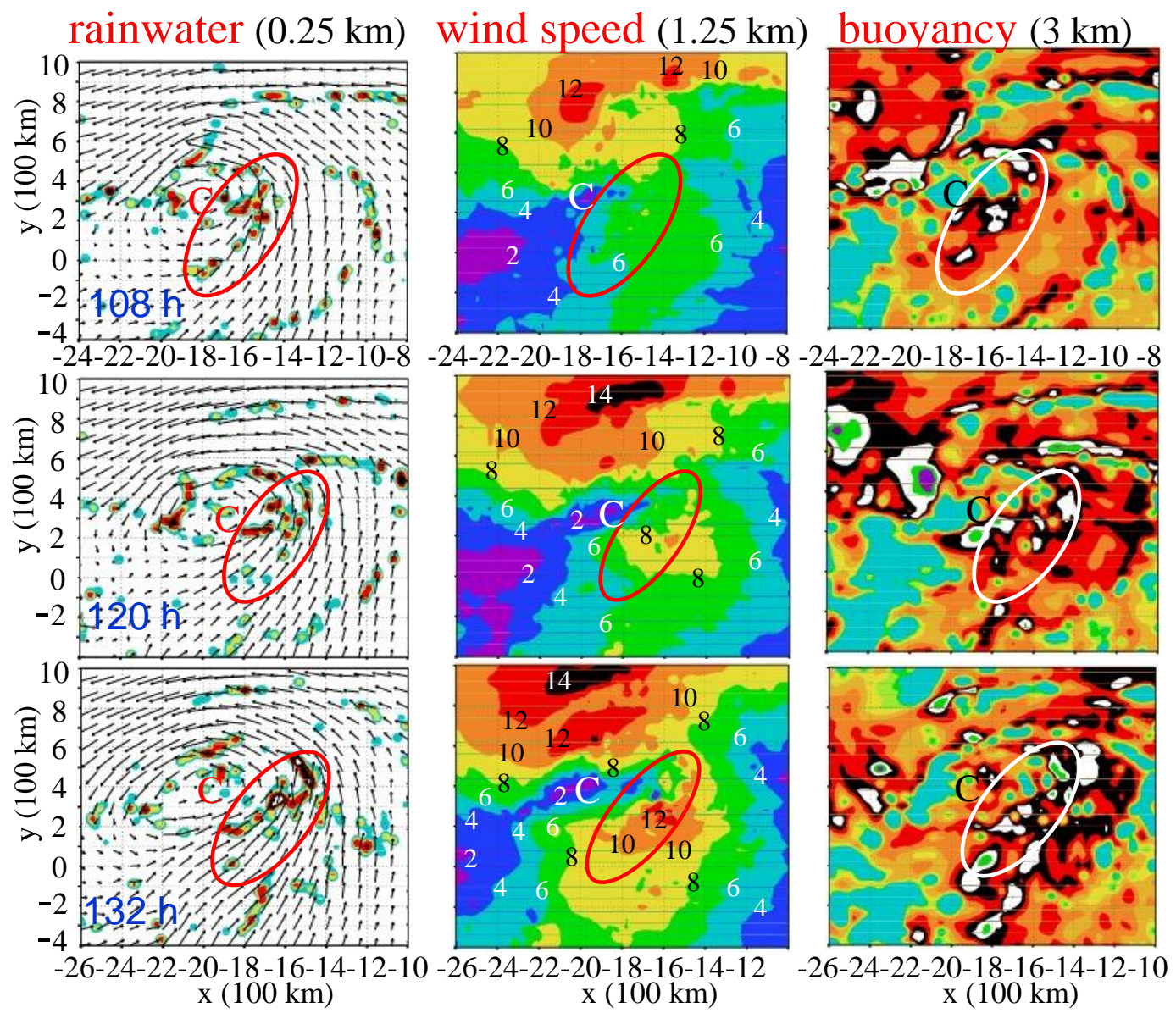

Fig. (8). Same as Fig. (7) except at 108h, 120h, and 132h. 

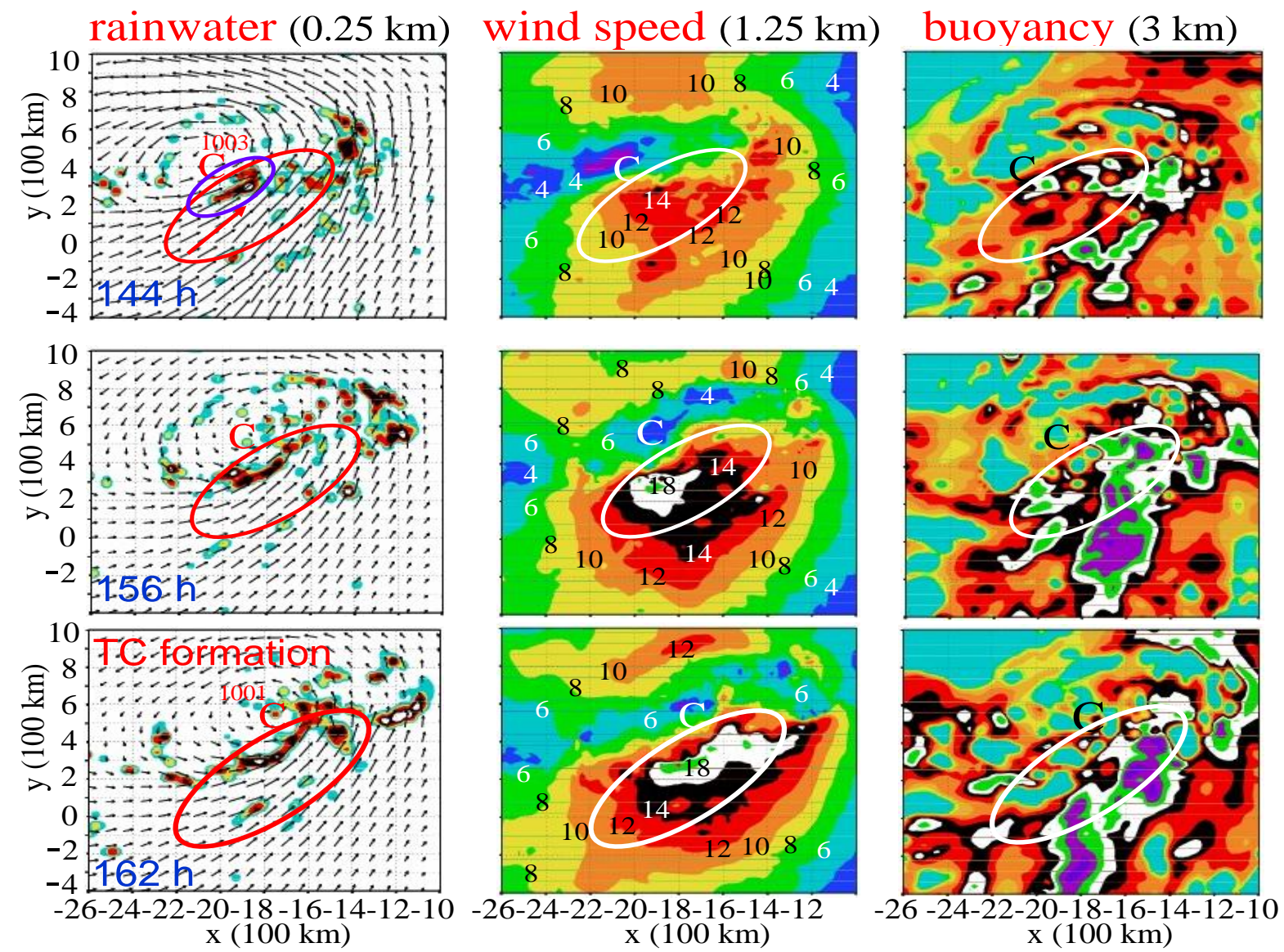

Fig. (9). Same as Fig. (7) except at 144h, 156h, and 162h (TC formation stage).
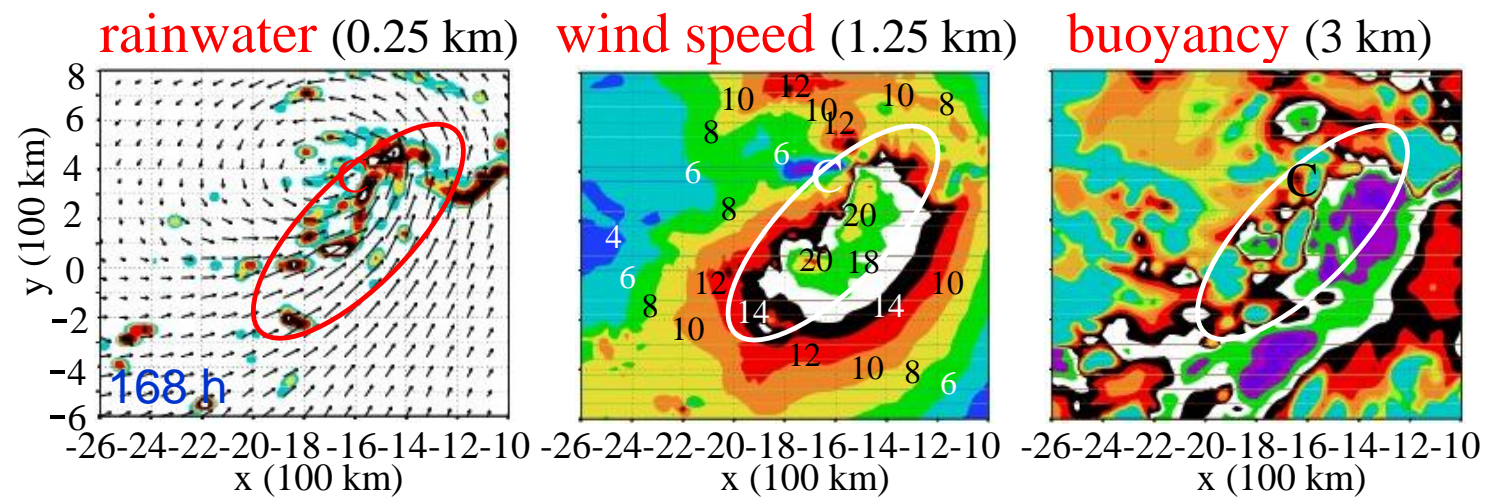

Fig. (10). Same as Fig. (7) except at 168h.

$\theta_{e}$ throughout the period shown. According to Figs. (8-10), a latently stable area appears in this area, and it intrudes cyclonically into the inner area of the vortex (or TC). Another feature is that $\theta_{e}$ is much lower in the southeastern area of the vortex than the northwestern until $120 \mathrm{~h}$ and these are comparable at $144 \mathrm{~h}$, whereas the buoyancy in the southeastern area (Figs. 7-9) is not very smaller before $120 \mathrm{~h}$ and it is much larger after $132 \mathrm{~h}$. These differences are due to the temperature difference at $3 \mathrm{~km}$, as mentioned before.

The author has been interested in several fields, particularly low-level rainwater, low-level flow pattern, lowlevel wind speed, and buoyancy (at a height of $3 \mathrm{~km}$ ) in these 25 years when he has intended to understand TC formation. The wind speed is a good measure of the vortex intensification, and the relation between convective activity (convective cloud distribution) and wind intensification has been understood to a fairly degree by the studies in these 50 years. The frictional flow, which strongly controls convective activity, is closely related to the low-level wind speed (and relative vorticity). As was mentioned, the vertical distribution of buoyancy of the rising air (or latent instability indicated by positive buoyancy) is also important to convective activity. The author has been most interested in the buoyancy at a height of $3 \mathrm{~km}$ as a good measure of latent 


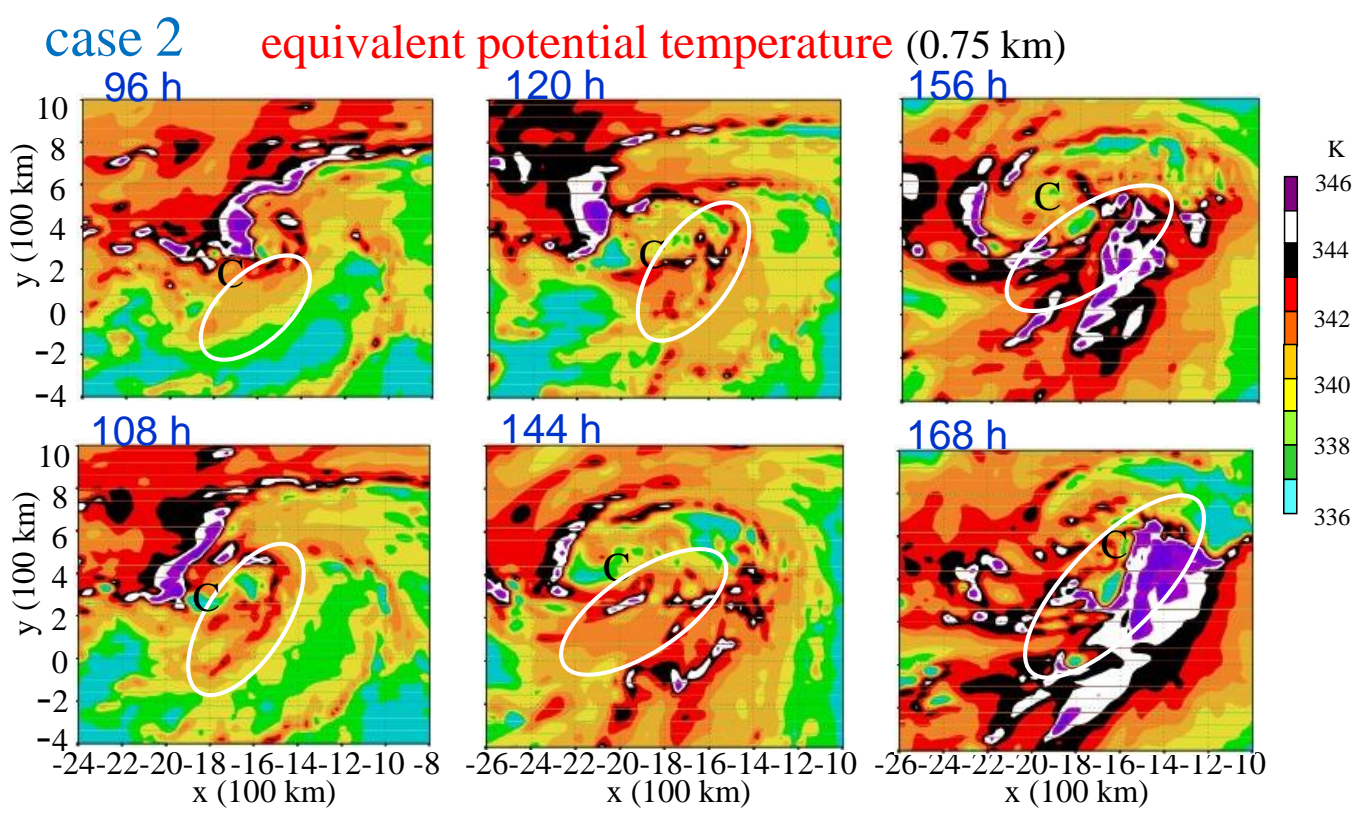

Fig. (11). Equivalent potential temperature at $0.75 \mathrm{~km}$ at several selected times in case 2 .

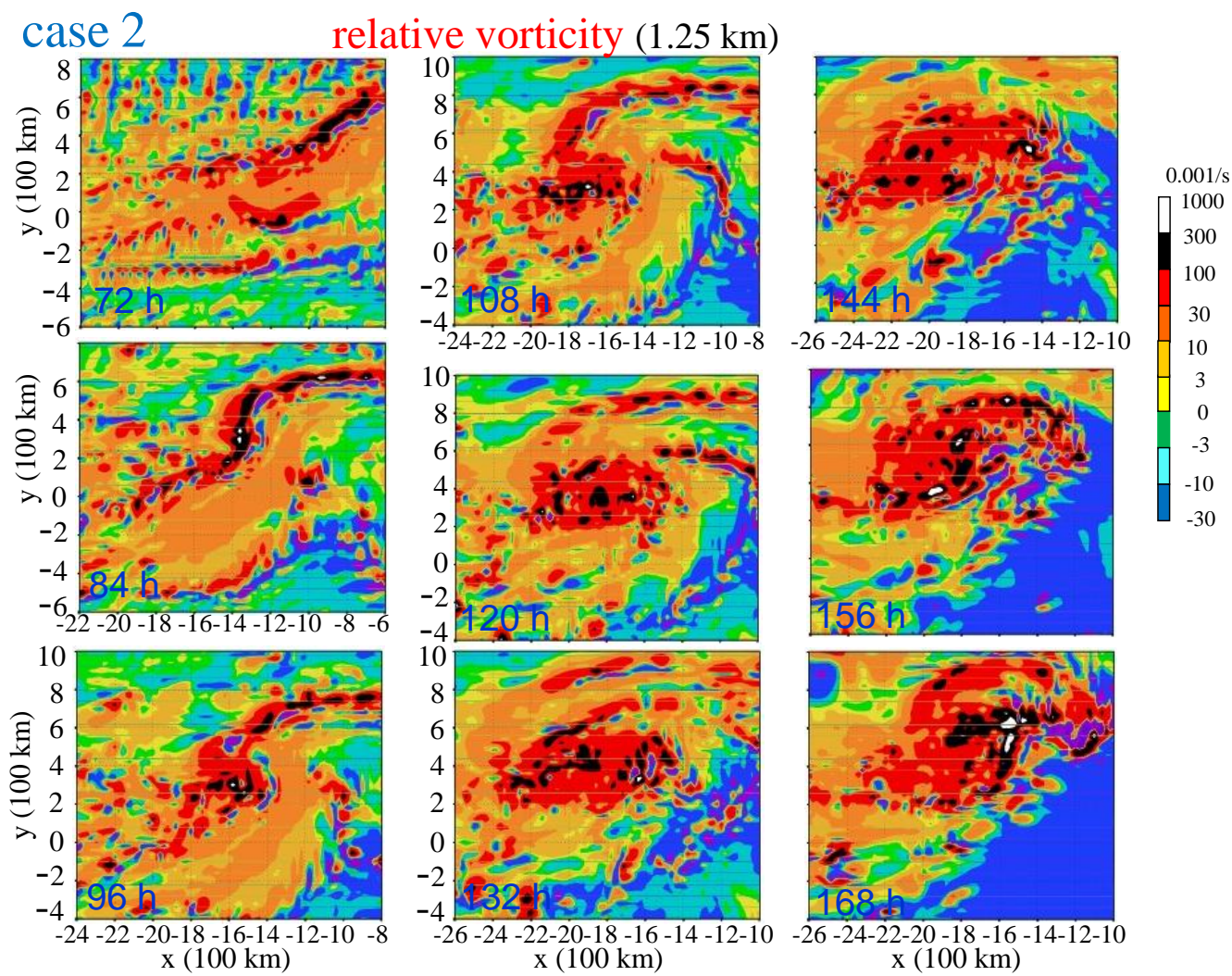

Fig. (12). Relative vorticity (vertical component) at $1.25 \mathrm{~km}$ at a time interval of 12 hours from $72 \mathrm{~h}$ to $168 \mathrm{~h}$ in case 2 .

instability rather than CAPE. Convective clouds can form in the ascending area with the low-level positive buoyancy.

On the other hand, the author has not been very interested in the vorticity field. Although it is easy to infer the vorticity field from the wind field, it is not easy to infer the wind field from the vorticity field in such a case of the complicated vorticity field as seen in the TC formation process. In recent years (particularly in these 10 years), many researchers have discussed the vorticity field to explain TC formation without referring to the wind speed field and the role of frictional flow. For reference, the vorticity field at a height of $1.2 \mathrm{~km}$ at several selected times in case 2 are shown in Fig. (12) (The left and middle panels correspond to Figs. (7) and (8), respectively. The right panels correspond to two panels of Fig. (9) and Fig. (10). Probably, it is not easy to infer TC formation from the time evolution of these vorticity fields. Large vorticity does not necessarily reflect the major 
convective systems that contribute to the vortex intensification and $\mathrm{TC}$ formation. It should be again emphasized that it is more important to examine the behavior of convective systems and the low-level wind field.

\section{CONCLUDING REMARKS}

This paper describes the results from numerical experiments which have been performed for better understanding of TC formation with a nonhydrostatic version [21] of the mesoscale-convection-resolving model (MCRM) [12, 13]. The horizontal grid size is taken to be 20 $\mathrm{km}$, as in the previous studies $[17,18]$, as a basis for global warming studies in the future.

An idealized (simplified) condition is used for the numerical experiments to make understanding easier; any other disturbances such as a subtropical high are not taken into account. The primary objectives of this study are to understand TC formation under a condition that any environmental flow does not exist (case 1), as a step toward better understanding, and then to understand the effects of an environmental easterly flow that does not have low-level vertical shear (case 2). In this study, we deal with TC formation associated with cloud clusters embedded in a synoptic-scale (about 2,000 km) vortex. Buoyancy perturbations are imposed at the initial time to obtain such a synoptic-scale vortex. Two band-shaped convective systems, which are oriented in the westsouthwest - eastnortheast direction, are also obtained to the north and the south of the vortex center in both cases.

Results from numerical experiments indicate that the southern band-shaped convective system (simply, convection) is stronger than the northern in case 1 , and the northern convection is stronger in case 2 . The wind is stronger to the south of the southern convection in case 1 and to the north of the northern convection in case 2. The equivalent potential temperature in the boundary layer and latent instability (positive buoyancy of rising air) are larger around and to the south of the southern convection in case 1 and around and to the north of the northern convection in case 2. Stronger winds to the north of the northern convection in case 2 is due to superposition of the environmental easterly flow and the vortex flow, and stronger latent instability in this area is due to higher equivalent potential temperature in the boundary layer, which is caused by the surface heat flux enhanced by stronger winds. On the other hand, in case 1, the latitudinal variation of the Coriolis parameter is important to produce stronger convection in the southern area. The feature that the maximum wind tends to be located to the southeast of the vortex center in the TC formation process and the abovementioned Coriolis effect have been understood, at least, since the 1980 s.

The most important result from case 2 is that the northerly flow to the north of the northern convection does not play an essential role in the maintenance of convection, intensification of the vortex, and TC formation, although the boundary layer air around and to the north of the northern convection has high equivalent potential temperature, and strong latent instability and very large horizontal shear (vorticity) exist in this area. In contrast, the important role of convective activity in an area to the southeast of the vortex center is emphasized. Although it is latently stable in an area to the south of the northern convective system at the early stage, it becomes latently unstable to the east-southeast of the vortex center owing to the surface heat flux. The southerly-southwesterly flow of the air that comes from the southern area plays an important role in the formation and maintenance of convective clouds, intensification of the vortex, and TC formation. This feature is also found in case 1 without environmental easterly flow.

Since the present study as well as the author's previous studies $[14,15,17,18]$ does not cover the whole aspects of TC formation processes, further studies are needed to better understand TC formation. As the next step of this study, the author has performed numerical experiments with a $2 \mathrm{~km}$ grid, which nearly corresponds to a cumulus-convectionresolving model (CCRM). In this case, relatively small TCs have been treated under the present computer restrictions. The effects of the ice cloud microphysics, surface friction, and the vertical shear of the environmental wind have been examined. Results will be reported in separate papers. Finally, it should be emphasized that TC formation processes should be more clarified by radar observations which can provide important information of low-level rainwater field.

\section{CONFLICT OF INTEREST}

The author confirms that this article content has no conflict of interest.

\section{ACKNOWLEDGEMENTS}

The numerical experiments have been performed with the use of the NEC SX-8R super computer in the Japan Agency for Marine-Earth Science and Technology.

\section{REFERENCES}

[1] Yamasaki M. Advances in basic understanding of tropical cyclone formation, The second WMO international workshop on tropical cyclones. WMO/TD-No.319. Manila: WMO Tropical Meteorology Research Programme Report Series 1989; Vol. 1: pp. 125-42.

[2] Yamasaki M. A view on tropical cyclones as CISK. J Meteorol Soc Jpn 2007; 85: 145-64.

[3] Ooyama K. Numerical simulation of the life cycle of tropical cyclones. J Atmos Sci 1969; 26: 3-40.

[4] Charney JG, Eliassen A. On the growth of the hurricane depression. J Atmos Sci 1964; 21: 68-75.

[5] Gray WM. Global view of the origin of tropical disturbances and storms. Mon Weather Rev 1968; 96: 669-700.

[6] Yamasaki M. A preliminary experiment of the tropical cyclone without parameterizing the effects of cumulus convection. J Meteorol Soc Jpn 1977; 55: 11-31.

[7] Yamasaki M. The role of surface friction in tropical cyclones. J Meteorol Soc Jpn 1977; 55: 559-72.

[8] Yamasaki M. A further study of the tropical cyclone without parameterizing the effects of cumulus convection. Papers Meteorol Geophys 1983; 34: 221-60.

[9] Kurihara Y, Tuleya RE. A numerical simulation study on the genesis of a tropical storm. Mon Weather Rev 1981; 109: 1629-53.

[10] Tuleya RE, Kurihara Y. A numerical study on the effects of environmental flow on tropical storm genesis. Mon Weather Rev 1981; 109: 2487-506.

[11] Ooyama KV. Conceptual evolution of the theory and modeling of the tropical cyclone. J Meteorol Soc Jpn 1982; 60: 369-79.

[12] Yamasaki M. A three-dimensional tropical cyclone model with parameterized cumulus convection. Papers Meteorol Geophys 1986; 37: 205-234.

[13] Yamasaki M. Parameterization of cumulus convection in a tropical cyclone model. Collection of papers presented at the WMO/IUGG NWP Symposium, Tokyo, 1986. J Meteorol Soc Jpn 1987; 65: 665-78. 
[14] Yamasaki M. Towards an understanding of the interaction between convection and the larger-scale in the tropics. Aust Meteorol Mag 1988; 36: 171-82.

[15] Yamasaki M. Numerical experiment of tropical cyclone formation in the intertropical convergence zone. J Meteorol Soc Jpn 1989; 67: $529-40$.

[16] Rotunno R, Emanuel KA. An air-sea interaction theory for tropical cyclones. Part II: Evolutionary study using a nonhydrostatic axisymmetric numerical model. J Atmos Sci 1987; 44: 542-61.

[17] Yamasaki M. A study of tropical cyclone formation with a $20-\mathrm{km}$ grid model. SOLA 2006; 2: 9-12.

[18] Yamasaki M. A numerical study of tropical cyclone formation from two mesoscale convective systems in a large-scale convective system. SOLA 2006; 2: 57-60.

[19] Yamasaki M. A tropical cyclone model resolving mesoscale organized convection with prognostic treatment of subgrid-scale cloud water. J Meteorol Soc Jpn 2001; 79: 637-55.
[20] Hendricks EA, Montgomery MT, Davis CA. The role of "vortical" hot towers in the formation of tropical cyclone Diana (1984). J Atmos Sci 2004; 61: 1209-32.

[21] Yamasaki M. Development of a nonhydrostatic version of the mesoscale-convection-resolving model and its application to the eyewall and spiral rainbands of tropical cyclones. J Meteorol Soc Jpn 2010; 88: 755-80.

[22] Yamasaki M. A Study of the 22 February 1993 TOGA COARE squall line: a case used for the GCSS model intercomparison. J Meteorol Soc Jpn 2004; 82: 1331-63.

[23] Yamasaki M. Toward an understanding of the Madden-Julian oscillation: with a mesoscale-convection-resolving model of 0.2 degree grid. Adv Meteorol 2011; 2011: 34 .

[24] Yamasaki M. A numerical study of cloud clusters and a meso- $a$ scale low associated with a Meiyu front. J Meteorol Soc Jpn 2005; 83: 305-29.

(C) Masanori Yamasaki; Licensee Bentham Open.

This is an open access article licensed under the terms of the Creative Commons Attribution Non-Commercial License (http: //creativecommons.org/licenses/by$\mathrm{nc} / 3.0 /$ ) which permits unrestricted, non-commercial use, distribution and reproduction in any medium, provided the work is properly cited. 